\title{
Taula rodona: \\ Q uè és investigar?: del marc institucional a les pràctiques
}

\author{
M oderadora: Teresa Torns \\ Universitat Autònoma de Barcelona. D epartament de Sociologia \\ 08193 Bellaterra (Barcelona). Spain
}

La recerca és allò que l'organització universitària ha situat dins els departaments, és a dir, el departament té responsabilitat en la recerca. Participen de la taula representants de grups i de maneres de fer recerca distintes dins el departament, no hi són tots perquè al públic també n'hi ha. El que volem mostrar ara no és tant el que fem i com ho fem, sinó què vol dir investigar en aquest marc institucional concret, la universitat en general, i quines són aquestes pràctiques.

\section{La Taula}

\section{J esús I zquierdo. D epartament de Sociologia}

En primer Iloc, cal fer unes consideracions inicials sobre investigar a la universitat, és a dir, situar allò que es fa en el context general. Aquests dies s'ha parlat dels problemes i de les necessitats d'avaluar, en definitiva, nosal tres tre ballem a la universitat i no podem fer allò que ens doni la gana. El marc bàsic, doncs, seria el següent: el professor universitari és: a) un treballador, és a dir, una persona que ven la seva força de treball per sobreviure, b) un treballador públic, és a dir, al servei de la societat que finança i paga la seva feina; en altres paraules, el comprador de la seva feina és la societat, no és l'Estat. Així, si el comprador és la societat i no és l'Estat, com obeeixo la societat - perquè el treball és un acte d'obediència - ? L'acte d'obediència, en primer lloc, es practicaria per la via de fer allò que se't diu a la comunitat de la qual es forma part, i aquí estaríem equiparant els poders pràctics amb el poder que dóna origen a aquests poders pràctics. M 'explico: Si parlem de democràcia hem de parlar de la voluntat de la majoria i en aquest moment la majoria al nostre país, el partit més votat, és l'abstenció, la qual cosa genera una gran dificultat per establir si serveixes a la societat quan obeeixes allò que et diuen que has de fer dins d'una determinada institució. C om he resolt aquest problema? Per la via de recordar que sóc treballadora, i això significa que obeeixo en els límits i obeeixo a consciència, d'allò que se'm demana explícitament, però no accepto ordres que no siguin explícites ni formalitzades. En el treball d'investigació les or- 
dres no són explícites ni estan formalitzades, per la qual cosa no tinc cap obligació d'obeir. No pretenc no obeir, tinc clar que he venut la meva força de treball i, a més, per mi és un orgull ser funcionària pública, i per tant encantada de rebre ordres de la comunitat; el que passa és que no les sento, per més que pari l'orella, i mentrestant sobrevisc amb l'obediència a unes certes ordres que són molt explícites i de les que depèn que cobri cada mes. Això del que depen que cobri cada més ho faig de cor i tant bé com puc, obeeixo però a més a cons ciència, dins els límits de les meves capacitats, fent allò que sóc capaç de fer. Així doncs, en l'àmbit de la investigació, fins que a mi no em diguin clarament que se'm mana investigar un cert tema, no ho faré, però si se'm mana ho faré, si se'm mana vol dir, si hi ha elements de coacció que em forcin a fer-ho. De moment no n'hi ha.

Per altra banda, realment em crea problemes de confusió el propi marc en què es desenvolupa la investigació. Q ui mana el professorat universitari? En principi depenem de departaments, però resulta que els professors dels departaments hem manifestat la necessitat de fer un treball interdisciplinari, transdisciplinari i pluridisciplinari. Com es resol això? És aquí on situaria els instituts d'investigació, amb la finalitat de sal tar aquesta barrera de les disciplines, creant un entorn universitari on un professor pogués investigar en un terreny d'intercanvi immediat amb professors d'altres llocs. El problema que es crea, és que els instituts estan configurats de manera autònoma, així que quan el professor investiga per a l'institut, això li suposa una càrrega de feina, i inversa ment el departament, per tal de cobrir aquesta mancança, rep un professor substitut que en principi té menys experiència i està menys qualificat que el professor que està absorbit totalment o parcialment per part de l'institut. Aquí hi ha tensions que són urgents, per exemple, una tensió urgent respecte de l'entorn investigador fóra la pregunta sobre «qui investiga?»; en principi, investiguen becaris, professors contractats o funcionaris i personal extern; crec que està poc regulat, malgrat que s'ha fet un esforç seriós, no s'ha posat en pràctica un marc laboral clar sobre l'estatut de les persones que investiguen. També cal tenir present què s'investiga: ¿podem considerar investigació un informe tècnic fet mitjançant un conveni amb una institució pública o amb una empre sa privada?

D 'altra banda, abans de parlar de la meva manera de treballar, vull deixar clar que no pretenc implícitament defensar una manera de treballar; perquè quedi clar que no en defenso cap, assenyalaré que els diferents estils d'investigació comporten certs avantatges per a les universitats. $\mathrm{No}$ hi ha un estil bo i un altre de dolent, cadascun té els seus avantatges, i n'hi ha alguns que són simplement il-legals, aquells que realitza un professor que està contractat a temps complet i treballa per a entitats de fora de la universitat que impliquen algun tipus de relació contractual professional. $\mathrm{H}$ i ha una tolerància respecte de petites intervencions com ara conferències, etc. Em refereixo a projectes d'entitat financera, i en grau de dedicació intens. Els beneficis de la investigació del professorat sota «comanda», i per tant perseguint el fet de tenir ingressos, 
poden ser l'adquisició de coneixements, l'obtenció d'ingressos que es poden traduir en infraestructura per a la universitat (llibres...). En definitiva, que una universitat tingui presència social no és poc important, i aquest tipus devies de treball donen tots aquests avantatges. Els perills que això presenta són que, en la mesura i en el grau que sha anat devaluant l'estatut del professor en tant que docent, el professor (per factors d'autoestima, de poder, de diners...) tendeixi a sentir-se cada vegada més atret per coses que no tenen a veure amb la docència i que tenen a veure amb activitats que li donen més presència social, i crec que això és un problema, perquè podria significar que persones molt valuoses, amb vàlua reconeguda internacionalment 0 a nivell autonòmic, s'anes sin allunyant de la docència i s'anessin dedicant només a la investigació. Però no m'atreveixo a dir que hi hagi models millors o pitjors.

Sobre la meva manera o model d'investigar, cal dir que he investigat de diverses maneres i l'espectre és tant ampli que fins i tot he treballat per a una multinacional passant per la universitat, he cobrat, no he cobrat, he fet projectes per a l'Administració pública, «tutti colori». H e sentit que entorns molt amplis són poc controlables, i a mi m'agrada el poder; poder vol dir que si l'espífio l'he espifiat jo i quesi està bé, ho fet bé jo. Q uan et bellugues en entorns molt amplis s'escapen moltes coses i per una persona a qui l'interessa sobretot la investigació fonamental i el treball teòric (com és el meu cas), és necessari el control, ja que l'autoria intel-lectual és d'una persona. Es pot discutir amb els altres, obrir camins i intercanviar, però el treball intel lectual d'aquest tipus em sembla que no es pot fer en equip, cosa que no vol dir no intercanviar. Q uan no treballes en equip pots no establir una relació entre parells, la veritat és que al treball que tenim ara en marxa, que és sobre l'acudit, no hi ha una relació entre parells, i prou que m'en ressenteixo, perquè, per una part, podríem dir que no tinc uns adversaris forts de les coses que dic i, per altra par,t he de dir que les meves experiències de descoberta intenses s'han produït en relació amb alumnes precisament perquè la gent no està tan configurada mentalment com perquè no sigui impertinent, i la impertinència és utilíssima. S'aprèn més dient bestieses que formal itzant correctament, i a mi això m'ha portat a la relació amb persones que podríem dir que, des del punt de vista de formació, no són parells. El tema d'enfrontar-se de cara amb parells, que en la meva manera de treballar és una absència, I'he resolt a través de repartir articles que he escrit, miro de buscar gent llunyana respecte de l'àmbit on treballo, per rebre les seves crítiques. A vegades rebo crítiques àmplies; per exemple, del treball que he rebut una crítica més sistemàtica i àmplia, ha esta d'una persona que suposadament no és un parell, en la mesura que ha entrat després al departament, que no és un funcionari, etc... Un article meu sobre el «vincle social » va ser criticat per J.A. N oguera de manera fonamentada i curosa, i vull agrair-li públicament l'esforç que ha fet. En canvi, costa enormement establir un vincle de debat, de crítica i és més fàcil que les relacions entre nosaltres siguin tenses, encara que sigui implícitament, per enveges, susceptibilitats i afanys de poder. I això dificulta molt el debat universitari, perquè és una comunitat massa tancada, però si passem més temps junts que amb la parella, per 
quèno convivim més? Perquè tenim coses no resoltes i que no són de caràcter intel·lectual.

\section{Fausto M iguélez. D epartament de Sociologia}

Inicio l'exposició amb el mateix tema que la M . Jesús: investigar a la universitat significa dues coses, s'investiga com a treballador o com a funcionari i es té l'obligació d'investigar. Seria útil que a la universitat hi hagués gent que només investiga, gent quefa docència i investiga... o diverses graduacions. D e fet, l'única cosa que tenim ara és una combinació, difícil de mantenir a vegades, però quese suposa ques'ha de mantenir, i aquesta dificultat és greu quan treballes, per exemple, amb gent d'altres països quetémés flexibilitat de la quetenim aquí. La segona funció de professor és la d'estudiós, una l'obligació per exigències dela ciència, 0 d'al tres que interpel'len el que fas, alhora que també per exigències del currículum, malauradament per alsjoves, perquè sense currículum dela investigació que derivi en publicacions, poca cosa es pot fer a la universitat.

Q uè he investigat? En aquest punt hi ha un principi fonamental que és el de l'autonomia de l'investigador, nosaltres hauríem de tenir només les limitacions que deriven del debat, de les exigències científiques, de la teoria, del que se sap, mai imposicions que siguin ni de la universitat, ni del ministeri, ni de la UE, ni de cap tipus d'empresa, i en aquest sentit els poso tots dins del mateix calaix. La universitat l'única cosa que ha de donar al s investigadors és suport, i si de cas posar mecanismes d'avaluació. Com pot fer-ho? N osaltres tenim aspectes molt pautats, a nivell legal i, en termes d'eficàcia de la recerca i de treball, hi hauria d'haver un acord pel qual cada any es redactés una espècie d'informe d'avaluació de cada grup o investigador que està fent recerca - perquè ho fa amb mitjants públics 0 amb finalitat pública-. Per què han de ser ocultes 0 semiocultes aquestes coses? I no ho dic només en termes de debat dels bonics resul tats teòrics que hem trobat, sinó també de la «cuina» de la investigació.

Com és possible estabilitzar la recerca? Segurament hi ha raons per poder investigar sol o en grup, això depèn de la pròpia voluntat, però crec que, com a entitat pública que és la universitat, hauríem de demanar que la universitat donés el màxim suport a aquells que volen coordinar-se. La universitat, via centres, instituts o grups, hauria de donar suport als que volen coordinar-se, com a forma de superar les limitacions de l'excessiva especial ització, o als que volen superar enfocaments sectorials o parcials. Paral.lelament la gent que vulgui fer recerca individualment, òbviament també ho ha de poder fer, i potser millor, amb la llibertat que dóna no tenir cap pressió de parells o d'imparells, però dit ara des del punt de vista institucional, la universitat hauria de tenir l'obligació de fomentar al màxim el suport, els recursos, perquè la recerca és pogués fer més en coordinació, en grup, utilitzant recursos de manera compartida i potenciant els recursos de recerca que té la universitat.

L'avaluació que ara existeix en la recerca en aquest país és pràcticament individual, es fa una mica d'avaluació col·lectiva o avaluacions conjuntes de grup, però majoritàriament és una avaluació individualitzada. D e vegades res- 
pon a la realitat, perquè sha fet la recerca individualment, però de vegades no, perquè s'ha fet recerca de manera col lectiva i hi hauria d'haver també mecanismes d'avaluació en aquests casos. S'avalua sobretot pel lloc on es publiquen les coses que es publiquen, i segurament és un criteri d'interès, però en les publicacions passa el mateix que amb altres tipus de relacions, si tens una xarxa de bones relacions amb determinades persones acabes publicant més fàcilment en determinades revistes que si en tens amb altres persones o no en tens. Per part de la universitat o d'instàncies públiques hi hauria d'haver mecanismes d'avaluació anteriors a la publicació que donessin la possibilitat de veure la qualitat de la recerca en termes de continguts, d'avenç teòric, de tècniques utilitzades, de canvis introduïts, i en funció d'aquesta avaluació, la universitat podria potenciar molt més les capacitats de publicació. L'avaluació és molt important i pot ser estimulant, s no es fa només amb criteris administrativistes, sinó per donar suport als investigadors. Així, finalment, la investigació o els resul tats de la investigació passarien a formar part del capital de tothom si efectivament la universitat tingués mecanismes de publicació del que s'investiga. Així s'evita ria que moltes recerques quedessin al cal aix del comitent o client, i si es que den coses sense publicar per exemple perquè no interessen a la persona que ho ha encarregat, és en part perquè els investigadors no som suficientment valents per fer valdrela nostra autoria. Si el client no vol publicar, l'investigador sí que pot, i si no, en el moment de firmar el contracte cal mirar que no hi hagi cap clàusula, de manera que si hi és, aquella investigació no s'ha de fer, ja que per definició qualsevol recerca ha de ser pública. N o tindria sentit una recerca que no pogués ser contrastada, cosa que vol dir que ha de ser pública, que s'ha de publicar. I si un contracte impedeix la publicació, la manera més fàcil de resoldre el problema és no fer-la. Estem en una posició bona per fer això, perquè com que ens paguen igualment, si fem recerca al menys que tinguem la llibertat i l'autonomia d'haver fet el que creiem que s'ha de fer.

Ú Itima qüestió sobre els recursos: crec que hi ha un problema molt important a la universitat, i és que, en primer $\|$ oc, no calen tants recursos per fer recerca en ciències socials, fonamentalment els recursos són necessaris per tenir una certa infraestructura, que garanteix que no ens hem de dedicar a tasques que si estiguéssin fetes o garantides donarien més temps per fer el pas d'investigar. S'han de tenir alguns recursos mínims, ja que també calen diners per a aquests recursos mínims, i el mecanisme actual a la universitat segons el qual s'investiga si es té un projecte de la D IG ICYT, o de la UE, o de la conselleria, o d'ajuntaments, o de ministeri... falla en una cosa fonamental, i és que la universitat hauria de tenir diners, i això ho lligo amb el tema de l'avaluació, per dedicar-los a la recerca bàsica o a aquella que no encarrega ningú, i ja sé que té diners, però en té molt pocs. Parlo del tipus de recerca que no paga cap ajuntament, ni ministeri, ni conselleria, però que la comunitat científica o un grup concret creu sincerament i contrastadament que és important. Si no tenim aquest tipus de recurs 0 aquest tipus de garanties, és més fàcil que ens decantem pel tipus de convocatòries que hi ha, on potser intencionadament es toquen temes que no es volen. 


\section{Salvador Cardús. D epartament de Sociologia}

D e fet, la meva experiència en el terreny de la recerca és fins i tot prèvia a la de la universitat, perquè abans d'acabar la carrera em vaig incorporar a l'ISO R i, per tant, al món de la recerca.

L'ISO R va néxer fa vint-i-cinc anys i fora del marc acadèmic, gràcies a una fundació que ara ha desaparegut. $\mathrm{H}$ a estat una plataforma extraordinàriament prima, és a dir, ha estat més un sostre, una cobertura formal que no pas un veritable centre de recerca, ha servit de cobertura de molta feina però no ha sigut una institució sòlida. $\mathrm{H}$ a sigut una estructura voluntàriament tan prima com ens ha convingut 0 com hem aconseguit que fos perquè fes la seva feina, però mai que fos una estructura més gruixuda del que necessitàvem i, en aquest sentit, també ha estat flexible: al Ilarg del temps hi ha hagut moments com en els primers anys que fins $i$ tot hi va haver una persona contractada fixa, però quan no ha sigut necessari o quan això ens podia comportar unes servituds que no estàvem disposats a assumir, ha desaparegut. Al cap de molt pocs anys d'haver-se creat I'ISO R ja vam intentar incorporar-lo a la universitat físicament, i així que va ser possible vam trobar un local on hi ha el material que durant aquests vinti-cinc anys s'ha anat incorporant a través del resultat de la pròpia feina. Aquest caràcter precari, des del punt de vista formal, de I'ISO R vol dir que ha sigut una estructura molt barata, que ha viscut en el primer temps d'una manera regular amb els ajuts d'aquella fundació, però després ha anat vivint amb petits ajuts intermitents de caràcter públic o semipúblic (Fundació Jaume Bofill, Fundació Juan $\mathrm{M}$ arch, Universitat de Boston...), sempre hem trobat al guns recursos que mai no han estat aplicats a una remuneració dels propis investigadors, sinó a adquirir material, per pagar algun treball de camp... Aquesta estructura prima ha comportat també la impossibilitat d'establir equips amplis i estables de treball, sempre hem crescut i hem disminuït en funció dels treballs i dels projectes que hi havia, seguint una estratègia d'acordió, però mai no ha arribat a estabilitzar-se res. $\mathrm{H}$ i ha dues persones que hi som des del primer dia, e J oan Estruch, ell hi és des del primer dia, i jo, quehi sóc des del segon, i després hi ha hagut gent que ha aprofitat aquesta mateixa estructura prima pel que li ha convingut; hi ha hagut gent que ha estat fent la seva tesi a dins de l'ISO R, ja que hi hem encabit tot el que ha convingut sense cap mena de condició de res.

$D$ arrerament també ha servit de cobertura perquè en algun cas apareixien alguns encàrrecs molt petits i molt marginals pel que eren les línies fonamentals de l'ISO R. Els hem acceptat, perquè ha semblat que podien ser un trampolí d'iniciació per a alguns estudiants que s'havien acabat de llicenciar, i si un consell comarcal demanava de fer un estudi sobre al guna cosa, es buscava algú que s'hagués llicenciat que pogués fer aquella feina, i nosaltres fèiem purament una feina de tutoria.

H em tingut consciència des del primer dia, des de l'any 74, que els nostres interessos intel. lectuals eren uns interessos relativament fora del mercat. Ja ho eren llavors, atès que l'any 74 estar interessats per temes de religió no era precisament el moment més adequat, però sempre han estat fora del que són 
les prioritats del mercat o del que són les prioritats del mercat acadèmic, no fora del que és I'interès acadèmic, perquè, d'altra banda, hem pogut comprovar al Ilarg dels anys, que en el marc internacional del que és el món acadèmic, allò que fèiem tenia algun tipus d'interès. $\mathrm{H}$ em tingut moltes i molt bones relacions amb universitats estrangeres, però en tot cas no formava part de les prioritats públiques de recerca i, per tant, això ho hem acceptat no només amb «cristiana» resignació, sinó també acceptant que aquesta era la condició de poder mantenir-nos en aquests interessos, que són més aviat teòrics, diríem en el millor sentit de la paraula, temàticament d'aparença marginal, però que això té un preu i el preu era no entrar en determinades competicions legítimes de tipus acadèmic. Jo crec que això no ens ha generat cap mala consciència ni cap irritació, perquè ens hem mirat amb una placidesa absoluta el fet de no disposar de grans projectes, potser és que som poc ambiciosos. No hem llegit enlloc unes instruccions precises que diguessin queaixò no es pot fer. N osaltres hem investigat. Q uan us repartim la memòria d'aquests vint-i-cinc anys veureu què és el que hem publicat, quantes coses hem publicat, hem organitzat i hem fet, és a dir, hem treballat molt però acceptant que això no formava part de les prioritats del moment. Jo crec que és defensable l'existència d'aquest tipus de treball acadèmic, d'allò que no forma part del que és el mercat més potent, de la recerca que incorpora aspectes marginals però importants per nosaltres. Per exemple, vam pensar que era una responsabilitat acadèmica nostra, i que a més diria que ens n'hem pogut aprofitar tots, el fet de poder disposar de bones traduccions al català de textos fonamentals per a la nostra docència o per a la recerca: la traducció de l'Estruch de L'ètica protestant i l'esperit del capitalisme jo crec que és un treball acadèmic de primer ordre, així com les traduccions del Berger, o de La construcció social de la realitat. Tots aquests llibres, que eren els que nosaltres necessitàvem, es feien des d'aquest mateix marc, sense grans sorolls, però ens semblava que podia ser interessant, i això és el que hem anat fent, hem anat adequant el nostre treball, i jo incorporo les traduccions dins del balanç de feina de recerca.

A vegades un també queda fora del mercat, no només perquè els seus temes són marginals o molt teorics, sinó també per raons poc democràtiques. Les avaluacions a vegades són molt opaques, de vegades tenen tonal itats polítiques, etc. Hi ha moltes altres raons per les quals un queda fora del mercat més competitiu, però ja dic que ni ens n'hem queixat. Per part meva també he entès que formava part de la meva feina, ja que era un cert tipus de vinculació amb la resta de la societat. El que vull dir és que moltes vegades que es parla de les relacions entre universitat i societat - i moltes vegades se' $n$ parla per veure què és el que paga la societat a la universitat, o quins projectes pot vendre la universitat a la societat- hi ha un tipus de relació més oberta i més pública que a mi em sembla que tambéés important. Jo no sé si queda fora o no queda fora del que és legítim que fem, però col·laborar en un determinat moment amb uns programes de televisió, o escriure articles a la premsa, o donar conferències en algun $\mathrm{lloc}$, o tenir iniciatives editorials, com dirigir una col·lecció dellibre universitari com he fet per l'editorial Proa i d'altres feines de divul- 
gació, ja sé que no és estrictament fer recerca, però és un tipus d'activitat que es pot incorporar perfectament a allò que fem.

Aquesta manera de treballar, jo no em veig amb cor de vendre-la, no només per la manera, sinó fins i tot no em veig amb cor de fer-ne virtut. Sé que té moltes pegues, i no per nosaltres, perquè subjectivament visc molt confortablement instal lat en la meva feina, no tinc mala consciència de no haver fet feina, però sí que entenc que té problemes, per exemple, pel que fa a la mateixa línia d'especialització. Sé que en part la feblesa quantitativa, i no sé si qua litativa - espero que no- del que és/'especialització en cultura, probablement té a veure amb una manera de treballar que ha fet que no poguéssim pressionar prou el D epartament, ni acadèmicament, per poder créixer d'una manera més notable, per tenir més professors especialitzats en aquest terreny, o bé perjudica directament els estudiants, de vegades acaben aquestes línies d'especialització i es qüestionen sobre el que es pot fer, i als quals no es pot dir que hom té una manera de treballar, que difícilment pot oferir-los res. És una manera de fer que té moltes limitacions. Per tant, no em veig amb cor de fer-ne virtut, sé que té molts límits, que és perjudicial, però de totes maneres no hem sabut fer una altra cosa, hem trobat una manera de fer, un tipus de treball, al qual tambés'ha incorporat altra gent, però que ha sigut el que era possible pel tipus d'objectius que ens proposàvem.

\section{Carlota Solé. D epartament de Sociologia}

Intentaré explicar breument, què és per mi investigar, com investigar, quins recursos es poden trobar, i després parlaré de les ten dències actuals en les formes d'investigar i els avantatges que té investigar a la universitat, a diferència de les empreses o d'altres entitats. Investigar respon a una decisió individual o personal, que potser té causes inconscients que potser des d'una perspectiva freudiana podríem explicar, però que, en fi, és quelcom que respon a una predisposició personal que de vegades es dóna i de vegades no es dóna tant 0 gens. En aquest sentit, si el fet d'investigar a la universitat es projecta a la docència, com a finalitat útima i legítima més clara, pot molt bé donar-se el cas de persones que combinin les dues activitats intel-lectuals. investigar i explicar el que $s^{\prime}$ ha investigat, per tal de transmetre els coneixements que ha adquirit. A la universitat, doncs, existeixen dostipus de professors, aquells que investiguen i fan docència i aquells que únicament fan docència. Això es dóna en altres universitats estrangeres encara més, on es potencia la investigació i es reconeix institucionalment aquesta tasca, i cal dir que aquest reconeixement ha estat iniciat a la nostra universitat des de fa poc. Considero que els professors universitaris com a treballadors o funcionaris som uns privilegiats, perquè tenim un grau d'autonomia molt alt en el desenvolupament de la nostra activitat - a part de veure gent jove cada dia davant nostre, la qual cosa és més agradable que veure cada dia les mateixes cares- , i en el que fem en els grups de recerca, i a més, com diria Collin-W rite, ens situem en els intersticis de les classes socials, així que mai ens sentirem subordinats o explotats per un altre grup social. U na 
altra qüestió sobre què és investigar és I'elecció del tema, això també respon a interessos, ideologies i creences que motiven i incentiven per anar a un cantó 0 a l'altre. És una elecció inconscient, que es plasma en una tasca molt racionalitzada, per no dir racional, amb uns mètodes molt treballats.

Com investigar? Es pot investigar individualment 0 a través d'equips de recerca. Individualment, es pot o s'ha d'investigar quan el tema és eminentment teòric, la reflexió teòrica és primerament molt individual, després en una segona fase apareixen els debats, es discuteix per tal d'enriquir-se personalment, però l'acte de pensar, reflexionar i d'argumentar-se a si mateix és un acte molt individual. Ara bé, en sociologia la reflexió teòrica i l'activitat empírica van molt lligades, aquesta primera forma d'investigar, bàsicament teòrica, en al guna part sempre s'ha de combinar amb recerca empírica. Per la meva experiència en temes de modernització, per exemple, vam fer un estudi sobre noves tecnologies i modernització, es va necessitar un equip d'investigació que fes entrevistes en profunditat, etc. Per tant sí que sempre hi ha una combinació de recerca empírica en temes teòrics, tret que es tractin temes més de filosofia social que no pas pròpiament sociològics. U na altra forma d'investigar fóra a còpia d'equips de recerca configurats en funció del que s'investiga. Això fa que es produeixin de vegades divisions de tasques, però hi ha sempre una coordinació centralitzada i diversos equips que treballen diversos apectes: aquí de nou la reflexió teòrica i el treball empíric hi són ben presents. Una tercera forma d'investigar fóra a través d'equips de recerca que han anat funcionant al Ilarg del temps, això respon a la creació de grups consolidats, com existeixen al nostre departament, grups o equips de recerca que s'impliquen en diversos projectes d'investigació. Són grups cohesionats que combinen el treball de reflexió amb el treball empíric de camp, i poden estar treballant amb un projecte 0 en diversos, amb una continuïtat al Ilarg del temps.

Pel que fa als recursos, aquesta és una tasca burocràtica i administrativa, confusa i pesada, perquè real ment un cop s'ha escollit el tema, que generalment a la universitat no és en funció de qui el vol pagar, s'ha de buscar un mínim de finançament. Es deia que es podia investigar sense diners i em sembla una mica difícil, cal un mínim de finançament. H i ha dues formes de finançament, en primer lloc el públic, al meu parer més preferible, ja que permet fer recerca sobre temes bàsics que no tenen una aplicabilitat immediata. Tot i que pugui ser indirectament condicionada, garanteix l'autonomia de l'investigador, la possibilitat d'investigació, perquè no hi ha els condicionants que fan que una investigació es quedi en un cal aix, sinó que es té molta més flexibilitat i poder de decisió per difondrela, ja que la investigació no només es fa de cara a la docència, si nó també de cara a donar-la a conèxxer, i ai xò serveix a altres investigadors per establir noves línies de recerca. Són petits grans de sorra que tots anem aportant al coneixement de la realitat social. En segon Iloc, el finançament privat presenta condicionaments més directes, sobretot en l'elecció del tema, però molt menys en la metodologia, ja que moltes empreses donen molta llibertat en l'aproximació al tema que proposen, tot i que pot haver-hi condicionaments a l'hora de publicar-lo. 
Un cop atorgat ja el finançament, quin és l'estatus dels investigadors, no dels directors de projecte, sinó dels investigadors que participen en grups de recerca? $\mathrm{H}$ an de cobrar una remuneració encara que sigui mínima, cosa que els permet avançar en temes que els interessin personalment o per a les tesis doctorals, i també per al currículum. Una possibilitat fóra el finançament mixt, que en al guns casos s'ha donat amb èxit.

Sobre les tendències actuals en la manera d'investigar, actualment està cada cop més present la forma coordinada d'equips d'investigació o entre diferents paiisos, com és la investigació a través de la Comissió Europea. Això té uns avantatges d'intercanvi de coneixements molt clars, però també té al guns obstacles, com les formes cultural ment diverses d'investigar dels diferents equips de països diferents. Hi ha una tendència a fomentar, fins i tot des d'organismes 0 entitats privades, la recerca bàsica, perquè es veuen els beneficis a llarg termini que poden derivar-se'n.

Els avantatges d'investigar a la universitat són: a) la cohesió dels grups de recerca, ja que els incentius no són primordialmet econòmics, sinó intel·lectuals, i aquesta comunitat d'interessos fa que els membres de l'equip puguin establir relacions fluïdes; b) la llibertat de decidir sobre noves línies d'investigació, i c) l'autonomia en la realització de l'activitat.

\section{El debat}

Treball en equip o context de treball

Actualment, un dels ajuts que la universitat dóna per a la recerca és la dotació de recursos per a la creació de grups emergents. Aquests grups poden seguir dos camins, l'un que se submergeixin novament, i l'altre que aconsegueixin consolidar-se. El treball en un grup consolidat, és a dir, amb una certa prolongació en el temps, en la durada i en l'estabilitat, presenta avantatges o aspectes positius que cal destacar: la transversal itat derivada de coneixements diversos, les inèrcies positives respecte als contactes que tenen els membres del grup i que poden constituir formes d'accedir a vies de finançament diverses i la creació d'equips de col·laboradors a través de becaris d'investigació. (Andreu Lope)

Els grups de treball, i la recerca de fonts de finançament, no han de ser pas incompatibles amb l'establiment dels interessos personals. N o obstant això, més que el treball en equip, el que interessa és un context de treball, més que un bon equip d'investigació, un bon context d'investigació, és a dir, un Iloc 0 un entorn on es pot investigar. (Lupicinio Íñiguez)

\section{La investigació: una obligació o una opció? La necessitat de vincular-la amb la docència}

Existeixen nombroses formes d'investigar, però també existeix la possibilitat de no fer-ho. És cert que la investigació és important per al currículum, és cert 
que tot professor cobra mal grat que no investigui, i és cert que la investigació està poc formalitzada, tot i que són obligatòries la docència, la investigació i la gestió. N o obstant això, hi ha persones que poden optar per no fer investigació o fer-ne poca. Aquesta és una opció vàlida, no des del punt de vista del'obligació laboral, sinó que té repercussions i efectes sobre el funcionament del departament, ja que part dels recursos que es destinen als departaments es donen en funció de la recerca feta, i si s'opta per dedicar-se només a la docència, aquests recursos no arriben. Per tant, el fet d'investigar o no investigar no es tracta d'una opció personal - sí el com investigar - sinó d'una obligació laboral. (Andreu Lope)

Respecte a les repercussions econòmiques que pugui tenir demanar ajuts 0 demanar-ne amb menys freqüència que altres grups d'investigació, es pot proposar de quantificar a quant surt per cap i que es reparteixi. El que es vol dir amb això és que el problema és més complex de com s'ha plantejat, és a dir, que cal analitzar aquesta pèrdua o guany de recursos i veure si es pot traduir en una manca de presència de professors estables (que es dediquen a investigació) i en l'aparició de contractes de substitució per cobrir aquestes absències. A banda de les necessitats de finançament del $D$ epartament, per exemple els recursos que arriben via cànon que es paga per investigació, no s'ha d'oblidar que el que està clarament formalitzat és la qüestió de la docència. És molt fàcil dir quan les classes no es donen bé o quan no satén bé un estudiant, però en canvi, és bastant més difícil dir en quina mesura un treball que es realitza és pura activitat d'informes professionals o quan és una activitat plenament universitària, en el sentit que fa una contribució positiva al coneixement facilitant-ne a més la transmissió. Les fronteres no són clares, però el que és clar és que està molt ben formalitzada la tasca professoral, i en un context en què aquesta s'està devaluant, cal fer una crida a recuperar la dignitat de docents, sense que això vulgui dir abandonar la investigació. (M . Jesús Izquierdo)

\section{La investigació: cap al mercat o cap a la societat?}

$\mathrm{H}$ i ha espais del treball d'investigació que tenen la responsabilitat de ser connectables, no amb el mercat sinó amb la societat. En aquest sentit, és cert que per a l'estudi de temes com el poder, la creació de subjectivitats, els processos d'inclusió i exclusió social, és difícil trobar diners per investigar, ja que no interessen al mercat, però es poden arribar a trobar bones combinatòries entre els interessos individuals i els interessos dels qui financen. N o obstant això, al mateix temps, aquesta connexió de la investigació amb la societat presenta un perill, i és que existeix l'estereotip de pensar que investigar amb responsablitat social es resol per la via de fer recerca per a ajuntaments, conselleries, sindicats, etc. Alhora existeix també l'estereotip que confon investigació amb investigació empírica, i la realitat és que existeixen investigacions no empíriques, que no per això són contemplatives, que poden tenir una ressonància important. (Lupicinio Íñiguez) 


\section{L'avaluació i els seus mecanismes}

Apel·lar a un criteri d'avaluació no significa apel·lar al reconeixement dels propis èxits, l'important és que un treball d'investigació sigui explicable, no tant que sigui eficaç o instrumental immediatament, ni que sigui recuperable per alguna instància social. L'important és que com a investigador es pugui respondre, des del punt de vista teòric, pràctic, social i polític, de la pròpia investigació, i és en aquest nivell de l'agència on no hi ha cap mecanisme d'avaluació, mentre sí que n'hi ha per al nivell de la productivitat o per a l'impacte social. Per tant, si es reivindica una avaluació transparent, no és perquè en general l'avaluació sigui individual i per a la gent que treballa en grups això és un inconvenient, sinó que es reivindica perquè la avaluació que es fa en aquest país, qualsevol que sigui la instància, és confusa, no és clara, es atzarosa i - almenys en psicologia - pendent de la voluntat dels catedràtics que tenen el poder. Avui en dia és més fàcil publicar un article en una revista estrangera, o un llibre en una editorial estrangera, que publicar un article en una revista del nostre entorn. (Lupicinio Íñiguez)

\section{La sortida professional o l'entrada a l'atur?}

Respecte a la qüestió dels becaris, com que no hi ha possibilitat de carrera ni de projecció professional, no només a la universitat sinó també en altres contextos, augmenta l'explotació. H i ha molts becaris entusiastes que treballen molt bé en equip, i és en aquests equips on estan profundament explotats; es tre balla gratis, com tothom fa quan existeix I'expectativa d'aconseguir un contracte d'ajudant o similar, però avui no existeix la possibilitat d'aconseguir un contracte de res. L 'únic que s'ofereix als investigadors joves són salaris de misèria, durant quatre o cinc anys que, en el millor dels casos, acabaran amb una tesi doctoral i després l'atur. N o es pot ser optimista respecte al mercat de treball que ofereix la investigació. (Lupicinio Íñiguez)

D es d'un altre punt de vista, es pot entendre que quan es fa una política de contractació de becaris, es dóna una oportunitat i es fa que responguin aquests becaris, hi ha la possibilitat d'escollir dos o tres anys de beca i potser després quedar aturat, o quedar aturat directament. Ser becari pot ser una feina de dos o tres anys que, tal i com estan les coses, acaba essent quasi un treball indefinit. (Fausto M iguélez)

N o obstant això, cal fugir de la visió reduccionista de la recerca com a estrictament universitària. Es pinta un marc tan estret de sortida professional, amb una recerca tan específica, que aparentment sembla que fora de la universiat no hi ha salvació. Existeixen molts tipus de feines que no són estrictament recerca d'alt nivell en el marc de la universitat, que poden constituir possibles sortides professionals. (Salvador Cardús) 